\title{
Внезапная смерть при респираторной патологии
}

ФГУ "НИИ пульмонологии ФМБА России": 105077, Москва, ул. 11-я Парковая, 32, к. 4

\section{A.L.Chernyaev, A.G.Chuchalin \\ Sudden death in respiratory patients}

Key words: sudden death, respiratory pathology.

Ключевые слова: внезапная смерть, респираторная патология.

Термин "внезапная смерть" используется в литературе более 250 лет, но до настоящего времени не существует единого определения. Проблема внезапной смерти (ВС) в последние годы приобретает все большее значение при разных видах патологии. Широк спектр ее причин, различно место наступления (внеили внутрибольничная), а также то, у здорового или больного человека произошла ВС.

Само определение, когда смерть может быть признана внезапной, варьируется в довольно широких пределах - от нескольких секунд до 24 ч. Большинство исследований посвящено внезапной сердечной (коронарной) смерти (ВСС) [1, 2].

Ранее ВСС определяли как смерть, развившуюся неожиданно у лиц, считавшихся здоровыми или находившихся в удовлетворительном состоянии, в течение 24 ч [3], 6 ч [4], 2 ч [5] от начала сердечного приступа. Выделяют также мгновенную смерть (несколько минут или секунд) [6]. По данным G.Baroldi et al. [7], 73 \% лиц умирают в течение первых 10 мин. Однако независимо от того, какой временной диапазон выбран, он остается условным, т. к. точно описать начальные симптомы крайне сложно.

Согласно Европейскому протоколу по исследованию ВСС, критерии ее достаточно четко очерчены: естественная, ненасильственная смерть, мгновенная или в течение 1 ч от начала симптомов [2]. Ежегодно в Западной Европе внезапно умирают до 300 тыс. человек старше 35 лет [1], в США - 300-400 тыс., или 1000 человек в сутки [8]. В возрасте 20-64 лет умирает $32 \%$ [9]. Отмечено, что эти люди чаще курили, принимали лекарственные препараты, кокаин, среди них преобладали лица негроидной расы.

ВС у больных с патологией органов дыхания описана фрагментарно и чаще касается действия отдельных лекарственных препаратов или редких видов патологии.

Тем не менее в Европейском протоколе по ВСС имеются необходимые указания по анализу таких смертей, а также перечислены множественные факторы риска, актуальные для больных с патологией легких, особенно лиц старше 50 лет при наличии артериальной гипертонии, атеросклероза, сахарного диабета, врожденных изменений интервала QT на ЭКГ, аритмии и кардиомиопатии разной этиологии.

Во всех наблюдениях клинически доказанной смерти в течение 1 ч у больных с патологией легких следует применять подход к исследованию, используемый в Европейском протоколе при ВСС, поскольку пациенты с хронической обструктивной болезнью легких (ХОБЛ) и идиопатическим легочным фиброзом (ИЛФ), как правило, старше 40 лет и имеют сочетанную сердечно-сосудистую патологию.

Необходимо, однако, заметить, что при патологии органов дыхания ВС может возникать вне зависимости от патологии сердца и сосудов.

К этому варианту ВС следует относить:

1) разрыв расслаивающей аневризмы легочной артерии (ЛА), чаще при идиопатической легочной гипертензии (ИЛГ) или без таковой;

2) ВС во время астматического статуса, наступающую в течение 1 ч.;

3) ВСС при передозировке $\beta_{2}$-агонистов с очагами ишемии (некроза) или без таковых у больных ХОБЛ и бронхиальной астмой (БА);

4) фибрилляцию желудочков при наличии легочного сердца (ЛС) при разных видах патологии легких (ИЛГ, ХОБЛ, ИЛФ, пневмокониоз, бронхоэктатическая болезнь, муковисцидоз, артерииты, токсические и радиационные воздействия, обструкция легочных сосудов, опухоли, метаболический ацидоз, гипоксемия, ЛС, сформировавшееся в условиях высокогорья, обструкция трахеи и главных бронхов);

5) сочетание патологии легких с различными видами кардиомиопатии;

6) случаи ВС у лиц с сонным апноэ, чаще страдающих ХОБЛ, крайней степенью ожирения и / или перенесших инфаркт миокарда.

Первая публикация о разрыве ЛА в 1862 г. принадлежит W.H.Walshe [10]. Всего к 2001 г. было опубликовано 48 наблюдений [11-13]. Причинами разрыва ЛА являются идиопатическая (ИЛГ) и вторичная легочная артериальная гипертензия (ВЛГ), а также болезни соединительной ткани, нередко сочетающиеся с патологией легких [14]. При этом в стенке ЛА развивается мукоидная дегенерация 


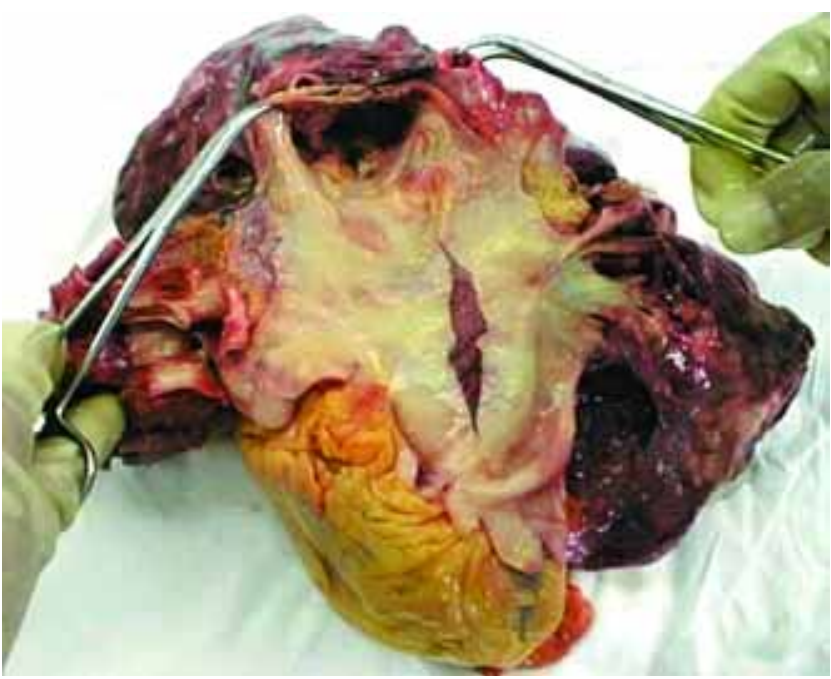

Рис. 1. Женщина 42 лет. Идиопатическая легочная гипертензия. Линейный разрыв аневризмы ствола легочной артерии, атеросклероз легочной артерии

медии и фрагментация эластических волокон, что обуславливает хрупкость сосудистой стенки. Такие изменения могут быть связаны с инфекцией, нарушениями эластической ткани, с высоким давлением в ЛА и размерами аневризмы (рис. 1). При ИЛГ разрыв аневризмы описан в 6 наблюдениях [12].

Из 4 описанных ВС при ВЛГ в 1 наблюдении имел место саркоидоз легких, в 2 - раковый лимфангоит легких и метастазы из аденокарциномы желудка, еще в 1 - ИЛГ носила семейный характер [15].

Описано, что при анализе 605 догоспитальных смертей в Макао ВС при ХОБЛ составила $11 \%$, при этом она не была связана с атеросклерозом венечных артерий [16].

За период с 1993 по 2000 гг. в США из 263 спортсменов, умерших внезапно во время занятий спортом, у 4 была БА [17]. ВС при БА является следствием асфиксии в течение 1,3 ч от появления симптомов [18, 19]. Считается, что в этих случаях преобладает спазм мускулатуры бронхов и особенно бронхиол над гиперпродукцией слизи (рис. 2). S.Sur et al. [20] описали 3 наблюдения смерти в течение 1 ч от начала симптомов. У этих умерших в собственной пластинке сли-

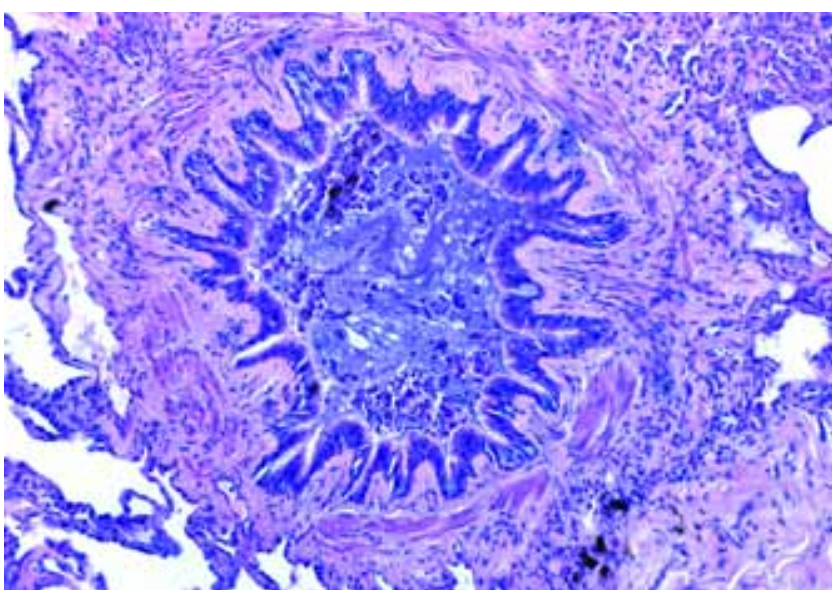

Рис. 2. Женщина 51 года. Атопическая БА. Закупорка слизью и десквамированным эпителием просвета терминальной бронхиолы. Окраска гематоксилином и эозином; × 40 зистой оболочки бронхов наблюдалось преобладание нейтрофилов над эозинофилами, и было показано, что число эозинофилов коррелирует с длительностью астматического статуса. ВС при БА может быть связана и с ингаляцией эндотоксинов. В Японии ВС при БА у взрослых составляет 29,3\%, причем почти в 1/2 случаев $(49,2 \%)$ она развивается при тяжелом течении заболевания. У детей при той же тяжести патологии она возникает в $43 \%$ наблюдений [19].

Вторым важным фактором в развитии ВС при БА и ХОБЛ является бесконтрольное использование $\beta_{2}$-агонистов и теофиллинов и, как следствие, их передозировка. Известно, что в миокарде левого желудочка и правого предсердия содержится $26 \%$ всех $\beta_{2}$-рецепторов. Усиление стимуляции рецепторов приводит к тахикардии, нарушению ритма сердца и, в конечном счете, к ишемии миокарда, что и является основной причиной ВСС [21]. Гипоксия и гипокалиемия, развивающиеся при использовании больших доз $\beta_{2}$-агонистов, приводят к удлинению интервала QT и аритмии, которые являются значимыми факторами риска и причиной развития ВСС [22, 23]. Возникновению аритмий также способствуют нарушения в проводящей системе сердца, вызванные передозировкой $\beta_{2}$-агонистов [24].

Считается, что фибрилляция желудочков сердца может возникать при ИЛГ, ХОБЛ и диффузных паренхиматозных заболеваний легких (ДПЗЛ) с формированием ЛС.

Причиной ВСС является ВЛГ, особенно у молодых спортсменов при гипертрофии миокарда (вес сердца > 500 г). При ЛС механизм ВСС связан с компрессией левого желудочка правым или регургитацией крови через 3-створчатый клапан при утолщении его створок и дилатации правого желудочка, что приводит к аритмии, асистолии, фибрилляции [25, 26].

Удлинение интервала QT на ЭКГ в настоящее время является одним из факторов риска ВСС при кардиоваскулярных и респираторных заболеваниях (в частности, при ХОБЛ, ДПЗЛ, БА) [27]. При этом электрокардиографическом синдроме (ЭКГ-синдроме) при молекулярной аутопсии выявлено существование особого гена, обозначаемого как HERY, с которым связывают аутосомно-доминантный тип наследования ЭКГ-синдрома [28]. Выявляют также аутосомно-рецессивное наследование при синдроме удлинения интервала QT, связанное с мутацией генов KCNQ1 (ZQT1), KCNE1 (LQT9). Развитие данного синдрома может быть также обусловлено мутациями по аутосомно-доминантному типу генов калиево-натриевых каналов KCNQ1 (LQT1), KCNH2 (LQT2), SCN5A (LQT3), калиевых KCNE1 (LQT5), KCNE2 (LQT6) и натриевых каналов SCN4B (LQT10), а также белковых генов ANK2 (LQT4) и CAV3 (LQT9) [29].

При наличии ЭКГ-синдрома короткого QT выявлены мутации генов ионно-калиевых каналов KCNH2, KCNJ2. При этом синдроме характерны обмороки (syncope), суправентрикулярные аритмии, короткий рефрактерный период и фибрилляция желудочков на ЭКГ [30]. 
Важной причиной ВСС является кардиомиопатия, которую разделяют на гипертрофичсекую и аритмогенную, на генетически обусловленную, смешанную и приобретенную. Одним из вариантов кардиомиопатии, которая может имитировать легочную гипертензию, является аритмогенная кардиомиопатия / дисплазия правого желудочка - АКПЖ / Д (правожелудочковая кардиомиопатия, болезнь Фонтана), иногда приводящая к разрыву правого желудочка, в основе которой лежит генный дефект 14q23q24, lq42-q43 [2, 31]. Болезнь более распространена среди мужчин, в 30-50 \% случаев имеет семейный анамнез. Распространение АКПЖ / Д колеблется от $1: 10000$ населения в США до $4: 1000$ в Италии. При этом считается, что АКПЖ / Д в $17 \%$ наблюдений является причиной ВСС [36,37]. Аневризма правого желудочка сердца описана на аутопсии при АКПЖ / Д у 50 \% умерших. В 50-70 \% наблюдений имеет место поражение левого желудочка сердца на поздних стадиях заболевания [34].

Вторым синдромом, который усугубляет или имитирует течение патологии легких, может быть синдром Бругада, в виде дисплазии правого желудочка с расстройством ритма и блокадой правой ножки пучка Гиса, обусловленный мутацией гена SCN5A, обнаруживаемого в $25 \%$ наблюдений [35].

Одним из важных факторов в развитии ВС у лиц, страдающих патологией легких, может быть гипертрофическая кардиомиопатия у спортсменов, которая является причиной смерти в $36 \%$ наблюдений, причем у лиц черной расы в 1,8 раза чаще, чем белой. Этот вид кардиомиопатии распознается, как правило, только при аутопсии [36]. Гистологическими признаками гипертрофической кардоимиопатии являются: хаотичное (разнонаправленное) расположение мышечных волокон, перинуклеарное просветление саркоплазмы, зазубренность контуров ядер кардиомиоцитов [37]. Важное значение при таких заболеваниях, как ХОБЛ и ИЛФ, приобретает сочетание с ними алкогольной (вторичной) кардиомиопатии. Развитие алкогольной кардиомиопатии свя-

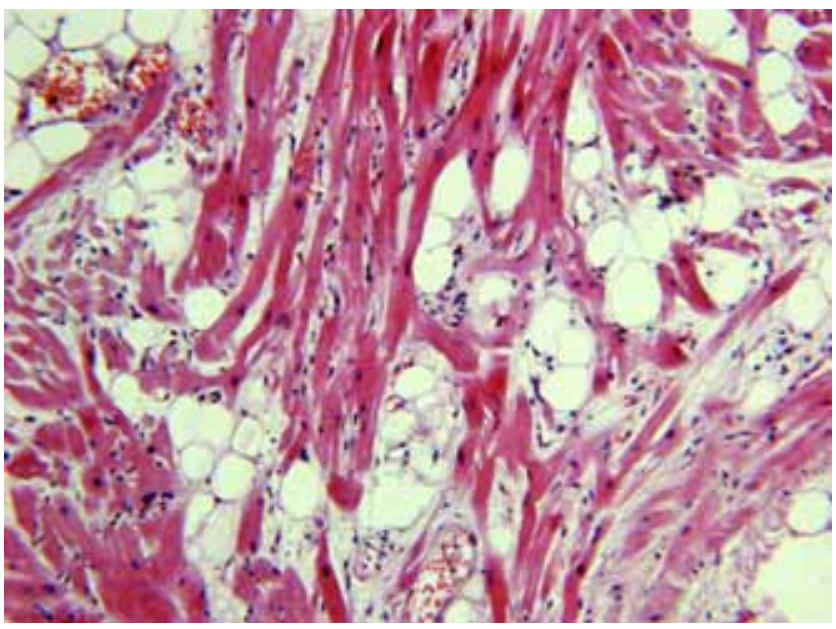

Рис. 3. Мужчина 49 лет. Алкогольная кардиомиопатия. Жировая межклеточная инфильтрация, разнонаправленное расположение кардиомиоцитов, сочетание гипертрофии и атрофии кардиомиоцитов. Окраска гематоксилином и эозином; $\times 100$ зано с цитотоксическим эффектом метаболита этанола, ацетальдегида, на клеточные мембраны, увеличивая их проницаемость. ВСС при алкогольной кардиомиопатии происходит за счет фатального нарушения сердечного ритма с развитием фибрилляции желудочков сердца [38]. Гистологически алкогольная кардиомиопатия характеризуется мелкокапельной жировой дистрофией кардиомиоцитов, внеклеточной жировой инфильтрацией вокруг сосудов, гипертрофией и атрофией кардиомиоцитов, сочетающиеся в одних и тех же полях зрения с очагами миолиза, плазморрагией, набуханием эндотелиоцитов сосудов, периваскулярными отеками (рис. 3).

С методической точки зрения все наблюдения ВС или ВСС должны подвергаться патологоанатомическому и / или судебно-медицинскому исследованиям с подробным изучением сердца и магистральных сосудов. Обязательно следует проводить токсикологическую экспертизу [39], а также "молекулярную аутопсию" с выявлением набора генов, ответственных за определенные ЭКГ-симптомы [29].

При патологоанатомическом исследовании необходимо изучать состояние венечных артерий сердца при поперечном их разрезе через каждые 3 мм. При этом оценивают выраженность атеросклероза, степень стеноза просвета сосудов бляшками, наличие кальциноза, кровоизлияний в бляшках, реканализованных тромбов, свежих тромбов в просвете сосудов. Считается, что факторами риска ВСС являются: стеноз венечных артерий > $75 \%$ просвета; наличие миокардиальных мостиков (погружение венечных артерий в миокард на отдельных участках ветвления); аномальное отхождение левой коронарной артерии; отхождение венечной артерии от легочной артерии; ранние и поздние изменения стентов [1]. Изучение миокарда следует проводить на циркулярных срезах, сделанных через 1 см через оба желудочка сердца от основания до верхушки [40].

Ведущим звеном пато- и танатогенеза ВСС является ишемия миокарда, сопровождающаяся тяжелыми нарушениями сердечного ритма в виде аритмий. При макроскопической диагностике ишемии миокарда во время аутопсии применяют окраску кусочков миокарда солями тетразолия, а при использовании теллурита калия и фосфатазы очаги ишемии практически не окрашиваются.

При проведении гистологического исследования при ВС в миокарде левого желудочка можно обнаружить очаги ишемии, видные при окраске гематоксилином и эозином, при окраске по Риго, Ли или при поляризационной микроскопии в виде контрактур или перерастяжения кардиомиоцитов. При этом можно наблюдать фрагментацию кардиомиоцитов (рис. 4) - иногда в сочетании с контрактурными изменений, что является признаком фибрилляции желудочков [37].

Проявлениями ишемии при ВСС являются: отек стромы миокарда; дистрофические изменения кардиомиоцитов (повышенная эозинофилия саркоплазмы, полосы сокращений, фуксинофилия, фуксиноррагия) (рис. 5) [41]. 


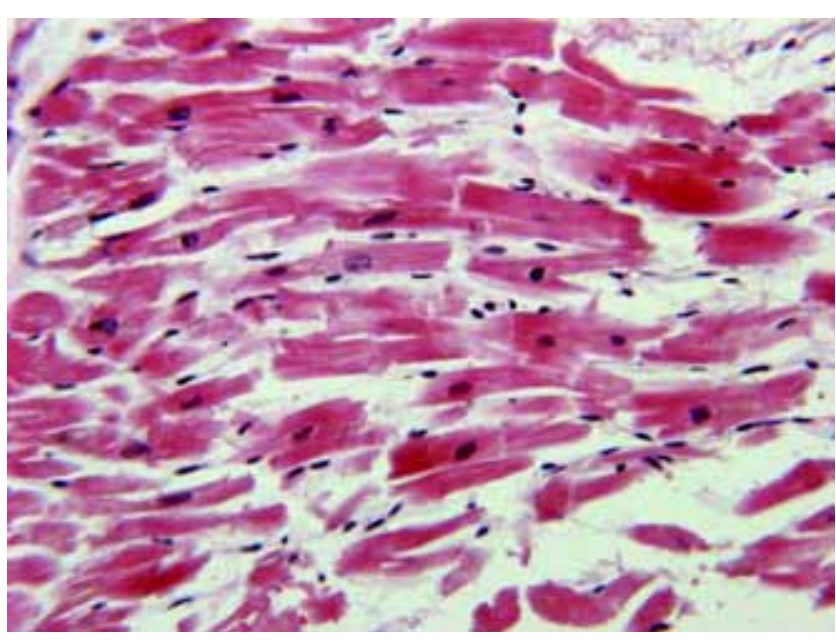

Рис. 4. Мужчина 60 лет. ВСС. Фрагментация кардиомиоцитов как доказательство фибрилляции желудочков

Контрактуры определяют с помощью поляризационной микроскопии, причем их объемная плотность в 13 раз больше, чем при насильственной смерти [37].

Расстройства кровообращения на уровне микроциркуляторного русла миокарда в виде неравномерного полнокровия являются еще одним важным признаком ишемии. Признается, что волнообразная деформация мышечных волокон также является критерием ишемии миокарда [42]. Этот феномен наблюдается от 15 мин до 6 ч от начала развития симптомов.

Показано, что при гистоферментохимических реакциях определяется исчезновение таких окислительно-восстановительных ферментов, как $\beta$-гидроксибутиратдегидрогеназа, малатдегидрогеназа, сукцинатдегидрогеназа, цитохромоксидаза [37, 41]. При электромикроскопическом исследовании к первичным ишемическим повреждениям относят: исчезновение гликогена; релаксацию миофибриллярного аппарата; появление аморфных липидных включений в митохондриях; набухание саркоплазматического ретикулума; пересокращение саркомеров; наличие плотных кальциевых включений в митохондриях; деформацию и расширение Z-полос; изви-

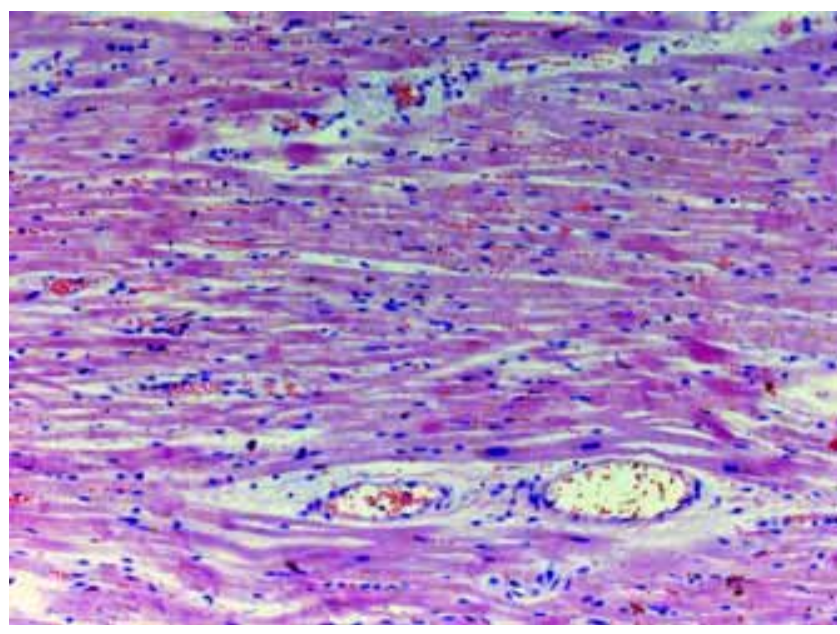

Рис. 5. Мужчина 65 лет. ВСС. Миоцитолизис, дистрофия кардиомицтов, полосы сокращения той вид вставочных дисков с диссоциацией их мембран [43].

Высокоинформативным методом идентификации ишемии миокарда является метод определения в гомогенатах сердечной мышцы калиево-натриевого соотношения (плазменная фотометрия), которое падает в этих зонах ниже 1,2 [44]. Еще одним способом определения ишемии миокарда при иммунопероксидазной реакции является исчезновение миоглобина в кардиомиоцитах при их гибели [45]. Кроме того, при иммуногистохимическом исследовании в зонах ишемии миокарда обнаружено исчезновение таких белков цитоскелета миокарда, как ванкулин, десмин, $\alpha$-актинин [46].

\section{Заключение}

До настоящего времени определение понятия "внезапная смерть" остается довольно расплывчатым. Рассматривая вопросы ВС, следует руководствоваться рекомендациями Европейского протокола по ВВС, в котором описаны патологоанатомические, токсикологические, молекулярные методы исследования. Частота ВС при заболеваниях легких сама по себе невелика и связана с такой патологией, как тромбоэмболия легочной артерии, разрыв аневризмы ЛА, астматический статус, передозировка $\beta_{2}$-агонистов при БА и ХОБЛ. Однако с учетом сочетания патологии легких с патологией сердечно-сосудистой системы проблема ВСС приобретает большое значение в практической пульмонологии. Особое значение в качестве риска развития ВСС у больных патологией органов дыхания имеют такие синдромы, как короткий и длинный интервал QТ на ЭКГ, синдром Бругада, катехоламиновые полиморфные желудочковые тахикардии, АКПЖ, гипертрофическая алкогольная кардиомиопатия. В дальнейшем следует разработать временные критерии установления диагноза ВС при заболеваниях органов дыхания.

\section{Литература}

1. Van der Wal A.C. Sudden coronary death. In: $21^{\text {st }}$ European congress of pathology. Update in pathology. Istanbul; 2007. 22-24.

2. Basso C, Burke M, Fornes P. et al. Guidelines for autopsy investigation of sudden cardiac death. Virchows Arch. 2008; 452 (1): 11-18.

3. Hecht A. Der acute Herztod- mit bezonderer Beruck sichtigung seiner atiologie und Pathogenese. Dtsch. Gesundh.Wes. 1979; 34 (28): 1297-1302.

4. Gunby P. Sudden death brings East and West together. J.A.M.A. 1998; 243 (3): 213-215.

5. Lie J.T. Pathology of sudden coronary death. Pathology 1983; 15 (3): 337-357.

6. Trolese-Mongheal Y., Duchene-Marrullaz P., Trolese J.-F. et al. Sudden death and experimental acute miocardial infarction. Am. J. Cardiol. 1985; 56 (10): 677-681.

7. Baroldi G., Falzi G., Mariani F. Sudden coronary death. Am. Heart J. 1979; 97 (1): 20-31.

8. Cina S.J., Smialek J.E., Burke A.P. et al. Primary cardiac tumors, caysing sudden death: a review of the literature. Am. J. Forens. Med. Pathol. 1996; 17 (4): 271-281. 
9. Lown B. Sudden cardiac death: the major challenge confronting contemporary cardiology. Am. J. Cardiol. 1979; 43 (2): $313-328$.

10. Watson A.J. Dissecting aneurysms of arteries other than the aorta. J. Pathol. Bacteriol. 1956; 72: 439-449.

11. Luctrath $H$. Dissecting aneurysm of the pulmonary artery. Virch. Arch. Abt. A. Pathol. Anat. 1981; 391: 241-247.

12. Steurer J., Jenni R., Medici T.C. et al. Dissecting aneurysm of pulmonary artery with pulmonary hypertension. Am. Rev. Respir. Dis. 1990; 142: 1219-1221.

13. Wally V.M., Virmani R.V., Silver M.D. Pulmonary arterial dissections and ruptures: to be considered in patients with pulmonary arterial hypertension presenting with cardiogenic shock or sudden death. Pathology 1990; 22: 1-4.

14. Senbaklavaci O., Kaneko Y., Bartunek A. et al. Rupture and dissection in pulmonary artery aneurysms: Incidence cause and treatment-review and cause report. J. Thorac. Cardiovasc. Surg. 2001; 121: 1006-1008.

15. Srigley J.A., Pollanen M.S. Sudden death with clinically undiagnosed pulmonary hypertension. J. Clin. Forens. Med. 2005; 12 (5): 264-267.

16. Wang H., Lei W., Li Y., Xu T. The epidemiology of nontraumatic prehospital sudden death in Macau. Resuscitation 2007; 74 (2): 222-226.

17. Becker J.M., Rogers J., Rossisni G. et al. Asthma deaths during sports: report of the 7-year experience. J. Allergy Clin. Immunol. 2004; 113 (2): 264-267.

18. Wasserfallen Y.-B. et al. Sudden asphyxic asthma: a distinct entity. Am. Rev. Respir. Dis. 1990; 142: 108-111.

19. Matsui T. Sudden asthma death: etiology and prevention. Nippon Rinsho 2005; 63 (7): 1214-1219.

20. Sur S., Crotty T.B., Kephart G.M. et al. Sudden-onset fatal asthma: a distinct entity with few eosinophils and relatively more neutrophiles in the airway submucosa? Am. Rev. Respir. Dis. 1993; 148: 713-719.

21. Salpeter S.R., Ormiston T.M., Salpeter E.E. Cardiovascular effects of $\beta$-agonists in patients with asthma and COPD. Chest 2004; 125: 2309-2321.

22. Suissa S., Hemmelgarn B., Blais L. et al. Bronchodilators and acute cardiac death. Am. J. Respir. Crit. Care Med. 1996; 154: 1598-1602.

23. Kallergis E.M., Manios E.G., Kanoupakis E.M. et al. Acute electrophysiologic effects of inhaled salbutamol in humans. Chest 2005; 127: 2057-2063.

24. Zipes D.P., Heger J.J., Prystowsky E.N. Sudden cardiac death. Am. J. Med. 1981; 70 (6): 1151-1154.

25. Wright J.N., Salem D. Sudden cardiac death and the "athlete's heart". Arch. Intern. Med. 1995; 155: 1473-1475.

26. Liberthson R.R. Sudden death from cardiac causes in children and young adults. N. Engl. J. Med. 1996; 334: 1039-1041.

27. Zulli R., Donati P., Nicosia F. et al. Increased QT dispersion: a negative prognostick finding in chronic obstructive pulmonary disease. Intern. Emerg. Med. 2006; 1 (4): 286-297.

28. Satler C.A., Walsh E.P., Vesely M.R. et al. Novel missense mutation in the cyclic nucleotide-binding domain of HERY causes the long QT syndrome. Am. J. Med. Genet. 1996; 65 (1): $27-35$.

29. Thiene G. Sudden death "Sine material" and molecular autopsy. In 21st European congress of pathology. Update in pathology. Istanbul; 2007. 25-27.
30. Priori S.G., Schwarts P.J., Napolitano C. et al. Risc stratification in the long-QT syndrome. N. Engl. J. Med. 2003; 348 (19): 1866-1874.

31. Basso C., Thiene G., Nava A. Dalla voltas arrhythmogenic right ventricularcardiomyopathy: a survey of the investigations at the university of Padua. Clin. Cardiol. 1997; 20 (4): 333-336.

32. Струтынский А.В., Глазунов А.Б., Бонзелюк Е.Н., Баранов А.П. Аритмогенная дисплазия правого желудочка. Лечеб. дело 2008; 4: 10-15.

33. McRae A.T. $3^{\text {rd }}$, Chung M.K., Asher C.R. Arrhythmogenic right ventricular cardiomyopathy: a cause of sudden death in young people. Cleveland Clin. J. Med. 2001; 68: 459-467.

34. Tabib A., Loire R., Chalabreysse L. et al. Circumstances of death and gross and microscopic observations in a series of 200 cases of sudden death associated with arrhythmogenic right ventricular cardiomyopathy and / or dysplasia. Circulation 2003; 108: 3000-3005.

35. Chen Q., Kirsh G.E., Zhang D. et al. Genetic basis and molecular mechanism for idiopathic ventricular fibrillation. Nature 1998; 19: 392 (6673): 293-296.

36. Maron B.J., Shirani J., Poliac L.C. et al. Sudden death in young competitive athletes. J.A.M.A. 1996; 276 (3): 199-204.

37. Кактурский Л.В. Внезапная сердечная смерть (клиническая морфология). М.: Медицина; 2004.

38. Вихерт А.М., Галахов И.Е., Матова Е.Е. и др. Гистология миокарда в случаях внезапной смерти. В кН. Внезапная смерть: Мат. 2-го Советско-Американского симмпозиума М.: Медицина; 1982. 130-150.

39. Fornes $P$. Sudden death and toxicological screening. In: $21^{\text {st }}$ European congress of pathology. Update in pathology. Istanbul; 2007. 25.

40. Basso C. Cardiomyopathies and sudden death. In: $21^{\text {st }}$ European congress of pathology. Update in pathology. Istanbul; 2007. 24-25.

41. Saukko P. Evaluation of diagnostic methods for early myocardial injury in sudden cardiac death. 1983 series D-n107 p. 3-55.

42. Bouchardy B., Majno G. Hystopathology of early myocardial infarcts. Am. J. Pathol. 1974; 74 (2): 301-330.

43. Цыпленкова В.Г., Вихерт А.М. Ультраструктура миокарда при внезапной сердечной смерти. Арх. пат. 1981; 4: 34-40.

44. Александри А.Л., Беспрозванный Б.К., Дедюева Е.Ю. О возможности посмертной диагностики причин внезапной смерти по распределению $\mathrm{K}^{+}$и $\mathrm{Na}^{+}$в миокарде. В кн. Материалы 1-го Всероссийского съезда судебных медиков. М.; 1981. 276-277.

45. Keil W., Ishiama I. Der myoglobin ver lust als erstet licht mikroskopisches zeichen einer Schadigung der HerzmusKelfasern. Dtsch. Gesundh.-Wes. 1984; 39 (7): 266-270.

46. Zhang J.M., Riddick L. Cytoskeleton immunohistochemical study of early ischemic myocardium. Forens. Sci. Int. 1996; 80 (3): 229-238.

\section{Информация об авторах}

Черняев Андрей Львович - д. м. н., проф., зав. отделом патологии НИИ пульмонологии ФМБА России; тел.: (495) 465-53-84; e-mail: samary @mail.ru

Чучалин Александр Григорьевич - акад. РАМН, д. М. н., проф., директор НИИ пульмонологии ФМБА России; тел.: (495) 465-52-64 